\title{
Perfil de Rousseau ${ }^{1}$
}

\author{
William Hazlitt
}

Tradução: Daniel Lago Monteiro

Doutorando em Letras pela USP

1 Título no original, "On the Character of Rousseau". Ensaio publicado pela primeira vez na revista The Examiner de 14 de abril de 1816 e, em seguida, reunido na primeira coletânea de ensaios do autor, The Round Table, 1817. (N.T.).

\section{discurso 43}



Em suas cartas sobre os escritos e o perfil (character) de Rousseau, Madame de Staël' defende a opinião de "que a imaginação foi a primeira das faculdades da mente do autor, por meio da qual ele absorveu, até mesmo, todas as demais" ${ }^{2}$. Ela acrescenta ainda que "Rousseau possuía uma grande força de raciocínio e a exercia sobre questões abstratas ou sobre objetos que só possuíam realidade no seu pensamento"3. Ambas as opiniões estão radicalmente erradas. Nem a imaginação tampouco a razão podem ser propriamente tidas como faculdades originalmente preponderantes na mente de Rousseau. A força de imaginação e de razão que possuía foi tomada de empréstimo dos excessos de outra faculdade; do mesmo modo, a origem de sua fraqueza e pobreza, as quais podem ser encontradas em sua obra, provém da mesma fonte; em outras palavras, para Rousseau, as faculdades da imaginação e da razão eram artificiais, secundárias, condicionadas por outra, e incapazes de operar senão por poderes a elas concedidos. A única faculdade que possuía em grau eminente, com a qual, e por si só, o elevou acima do homem comum e deu aos seus escritos e opiniões uma influência maior do que, talvez, jamais fora exercida por qualquer outro indivíduo nos tempos modernos, foi sua sensibilidade extrema ou sensação aguda, e até mesmo mórbida, de tudo o que estivesse relacionado às suas impressões sobre os objetos e os acontecimentos de sua vida. Nenhum outro homem teve uma consciência mais intensa de sua própria existência. Um objeto que tivesse outrora produzido uma impressão sobre ele jamais se extinguia. Toda sensação de sua mente se tornava uma paixão. $\mathrm{O}$ seu entusiasmo era um apetite e uma doença. $\mathrm{O}$ interesse em

1 Anne Louise Germaine de Staël-Holstein (1766-1817). Escritora franco-suíça, cuja influência no gosto literário se fez sentir por toda a Europa de seu tempo. A obra Lettres sur les ouvrages et le caractère de J. J. Rousseau foi publicada em 1788 (N.T.).

2 "Je crois que l'imagination étoit la première de ses facultès, et qu'elle absorboit même toutes les autres". P. 8o. (N.A.).

3 "Il avoit une grande puissance de raison sur les matieres abstraites, sur les objets qui n'ont de realité que dans la pensée”, e etc. P. 81. (N.A.). 
seus próprios pensamentos e sensações era sempre elevado ao ponto mais alto, por isso sua capacidade de produzir semelhante entusiasmo nos outros. $\mathrm{O}$ poder que exerceu sobre a opinião de toda a Europa, com o qual criou inúmeras disciplinas e subverteu sistemas estabelecidos, se deve, num primeiro momento, à tirania que as sensações exerciam sobre ele. $\mathrm{O}$ fulgor ofuscante de sua reputação irradiou com a mesma chama que o dotou de vida4. Suas ideias só se diferem em força e em intensidade das ideias de outros homens. Seu gênio decorre de seu temperamento. Nada criou e demonstrou pelo esforço isolado do entendimento. Suas personagens fictícias são modificações de seu próprio ser, reflexos e sombras de si mesmo. Suas especulações são exageros óbvios de um espírito entregue livremente aos impulsos habituais, que deu forma à natureza segundo os seus propósitos particulares. Donde o entusiasmo de sua eloquência, capaz de derrubar toda oposição. Donde o ardor, a luxúria e mesmo a uniformidade de suas descrições. Donde a habitual verbosidade de seu estilo, pois a paixão dá força e realidade à linguagem, faz com que as palavras ocupem o lugar da imaginação. Donde a tenacidade de sua lógica, a agudeza de suas observações e o refinamento de seus raciocínios, por mais inconsistentes que fossem. Donde a sua perspicácia penetrante aliada à estranha falta de compreensão da mente humana.

4 Ele contribuiu para a Revolução Francesa mais do que qualquer outro homem; Voltaire, com sua perspicaz força de vontade, tornou a superstição desprezível e a tirania odiosa. Mas foi Rousseau que trouxe para o peito de cada um o sentimento irreconciliável de inimizade para com as distinções sociais e o privilégio acima do sentimento de humanidade que ele identificou, a um só tempo, com todo o orgulho de intelecto e com os anseios mais profundos do coração humano. (O trecho a seguir foi suprimido na edição final, em The Round Table, N.T) Foi o fundador do jacobinismo - movimento de ideias que repudia a divisão dos homens em duas classes, uma como propriedade da outra. Foi com relação aos discípulos dessa escola que disse Burke, e o disse com muita precisão: "Uma vez jacobino, sempre jacobino!". Para os adeptos dela, uma ofensa política se confunde com o insulto pessoal. É este o modo de colocar o problema: a verdadeira levedura revolucionária só é despertada se o amor-próprio que espreita no fundo de todo coração entra em cena, e foi esse o modo como se expressou o próprio Rousseau. A questão se torna, então, entre o homem e o homem, e só há uma única maneira de decidi-la! 
Pois a mesma intensidade de sentimento que o permitia discernir os princípios primeiros das coisas, apoderando-se de uma única visão do objeto em todas as suas diferentes ramificações, impedia-o de admitir a operação de outras causas que interviessem no seu propósito preferido e o envolvesse em infinitas e infindáveis contradições. Donde o seu egotismo excessivo, que preenchia todos os objetos de si mesmo e com o qual teria esvaziado o universo inteiro de todo interesse. Donde a sua inveja e suspeita dos demais, porque nenhuma atenção, respeito ou simpatia poderia se aproximar das exigências de seu amor-próprio. Donde o modo com o qual ele se distraía consigo mesmo e com os objetos ao seu redor, porque nada poderia saciar o seu anseio ardente pelo bem e os apetites impacientes de seu ser. Donde as suas sensações extenuadas por tensões excessivas recaíam sobre si mesmas e produziam seu amor pelo silêncio e pelo repouso, e aspirações febris pela natureza serena e solitária. Donde, em parte, suas querelas com as instituições artificiais e com as distinções em sociedade que impuseram tantos obstáculos às indulgências desenfreadas de sua vontade e seduziram sua imaginação com cenários de simplicidade pastoral e de vida selvagem onde as paixões sequer seriam excitadas ou seguiriam o fluxo livre de seus impulsos, onde não haveria lugar para as vexações mesquinhas e as frustrações irritantes da vida comum e onde as ocupações perturbadoras das artes e das ciências se perderiam no contentamento animal ou no repouso indolente. Assim ele descreveu o primeiro selvagem em uma eterna caminhada sob as sombras de florestas magníficas ou sob as margens de um rio pujante, inflamado com o amor insaciável pela natureza!

A melhor de suas obras são as Confissões, embora seja a menos lida, porque contém menos dos conjuntos de paradoxos ou de opiniões gerais. Ela se refere inteiramente ao autor e ninguém se sentia tão em casa neste tema quanto Rousseau. Pela forte influência que as sensações se apoderavam de sua mente, ele nos fez entrar em seus sentimentos como se fossem nossos e nos lembrar 
de cada incidente e circunstância de sua vida como se tivessem ocorridos a nós mesmos. Nunca nos cansamos desta obra, pois a cada momento ela nos revela uma nova imagem que imaginamos ser a contraparte de nossa própria existência. São inúmeras as passagens desta espécie. Há o interessante relato de sua infância, no qual são tão bem descritos os constrangimentos e as liberdades irrefletidas quando, por exemplo, varava a noite lendo romances com seu pai até se verem forçados a abandonar a leitura pelo som matinal das andorinhas em seus ninhos; sua travessia dos Alpes, descrita com todas as sensações que lhe pertencem: o prazer de se sentar ao ar livre, a satisfação de ver a viagem chegar ao fim e o prazer "de andar sem saber para onde"; sua chegada a Turim; a figura de Madame Basile, retratada com precisão e elegância inimitáveis; as agradáveis aventuras de Chateau de Toune, quando passou o dia na companhia de Mademoiselle G e Mademoiselle Galley; a história de Zulietta, a orgulhosa e encantadora Zulietta, cujas palavras finais, "Va Zanetto, e studia la Matematica" , jamais serão esquecidas; quando dormiu nas proximidades de Lyon no nicho de um muro após um lindo dia de verão, junto ao empoleiro do rouxinol; seu primeiro encontro com Madame Warens, a pompa do som com que celebrou o seu nome dizendo-lhe: "Louise Eleonore de Warens etoit une demoiselle de la Tour de Pil, noble et ancienne famille de Vevai, ville du pays de Vaud"6 (sons que ainda soam trêmulos nos ouvidos); a descrição da Madame, o seu sorriso angelical e a semelhança do tamanho de sua boca à dele; sua repente saída vespertina enquanto os sinos entoavam e anunciavam, numa espécie de sonho acordado, a vida que doravante compartilharia ao lado dela, na qual compartilhariam meses, anos e a vida inteira em uma felicidade serena; a súbita frustração de suas esperanças; o modo como fora arreba- 
tado há trinta anos ao ver a mesma flor que trouxera para casa após uma de suas caminhadas pelas proximidades de Chambery; os pensamentos que teve durante esse longo intervalo de tempo; os jantares com Grimm e Diderot depois de sua chegada a Paris; a primeira ideia de sua premiada dissertação sobre o estado de natureza; o relato da escrita de A Nova Heloísa e sua ligação com Madame d'Houdetot; seus projetos literários, sua fama, seus infortúnios e o seu temperamento infeliz; seu último e solitário retiro no lago e na Ilha de Bienne acompanhado de um cachorro e um barco; os devaneios e as meditações encantadoras que teve ali; tudo isso permanece em nossas mentes apinhado de rememorações sobre as quais somos incapazes de expressar. Não há nenhuma passagem em A Nova Heloísa de força e beleza igualáveis às melhores descrições das Confissões, exceto a excursão para o lago e a última carta de Júlia para St. Preux, bem como a deste para aquela relembrando os dias de seus primeiros amores. Passamos dois anos inteiros lendo essas duas obras e vertendo lágrimas sobre elas (caros leitores, éramos jovens).

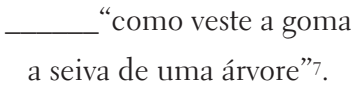

Foram os anos mais felizes de nossas vidas. Poderíamos dizer sobre eles: doce é o orvalho de suas memórias e prazeroso o bálsamo de suas recordações! Há, de fato, impressões que nem o tempo nem as circunstâncias podem apagar ${ }^{8}$.

7 Otelo, V, II. 350-1. Tradução de Bárbara Heliodora. Trecho no original, "As fast as the Arabian trees/ Their Medicinal gums".

8 Apresentamos aqui uma única passagem como exemplo que sempre nos pareceu a própria perfeição dessa espécie de descrição pessoal e local, a saber: aquela em que Rousseau relata sua experiência de corista na Catedral de Chambery: "On jugera bien que la vie de la maîtrise toujours chantante et gaie, avec les Musiciens et les Enfans de ch ur, me plaisoit plus que cella du Séminaire avec les Peres de S. Lazare. Cependant, cette vie, pour être plus libre, n'en étoit pas moins égale et réglée. J'étois fait pour aimer l'independence et pour n'en abuser jamais. Durant six mois entiers, 
je ne sortis pas une seule fois, que pour aller chez Maman ou à l'Église, et je n'en fus pas même tenté. Cet intervalle est un de ceux où j'ai vécu dans le plus grand clame, et que je me suis rappelés avec le plus de plaisir. Dans les situations diverses où je me suis trouvé, quelques uns ont été marqués par un tel sentiment de bien-être, qu'en les remémorant j'en suis affecté comme si j'y étois encore. Non seulement je me rappele les tems, les lieux, les personnes, mais tous les objets environnans, la température de l'air, son odeur, sa couleur, une certaine impression locale qui ne s'est fait sentir que là, et dont le souvenir vif m'y transporte de nouveau. Par exemple, tout ce qu'on répétait a la maîtrise, tout ce qu'on chantoit au ch ur, tout ce qu'on y faisoit, le bel et noble habit des Chanoines, les chasubles des Prêtres, les entres des Chantres, la figure des Musiciens, un vieux Charpentier boiteux qui jouoit de la contrebasse, un petit Abbé blondin qui jouoit du violon, le lambeau de soutane qu'après avoir posé son épée, M. le Maître endossoit par-dessus son habit laïque, et le beau surplis fin dont il en couvrait les loques pour aller au ch ur; l'orgueil avec lequel j'allois, tenant ma petite flûte à bec, m'establir dans l'orchestre, à la tribune, pour un petit bout de récit que M. le Maître avoit fait exprès pour moi : le bon diner qui nous attendoit ensuite, le bon appétit qu'on $y$ portoit: - ce concours d'objets vivement retracé m'a cent fois charmé dans ma mémoire, autant et plus que dans la realité. J'ai gardé toujours une affection tendre pour un certain air du Conditor alme syderum qui marche par iambes; parce qu'un Dimanche de l'Avent j'entendis de mon lit chanter cette hymne, avant le jour, sur le perron de la Cathédrale, selon un rite de cette église là. Mlle. Merceret, femme de chambre de Maman, savoit un peu de musique; je n'oublierai jamais un petit motet Afferte, que M. le Maître me fit chanter avec elle, et que sa maîtresse écoutait avec tant de plaisir. Enfin tout, jusqu'a la bonne servante Perrine, qui étoit si bonne fille, et que les enfans de ch ur faisoient tant endêver - tout dans les souvenirs de ces tems de bonheur et d'innocence revient souvent me ravir et m'attrister". Confessions, LIV. Iii. P. 283. [N.A.]. "É fácil de compreender que a vida da escola de canto, sempre alegre e ruidosa, agradava-me muito mais do que a vida do seminário com os padres de São Lazaro. E essa vida, entretanto, embora fosse mais livre, não era menos igual e regular. Eu era feito para amar a independência e nunca abusar dela. Durante seis meses não saí uma única vez, senão para ir à casa de mamãe ou à igreja, e nem tive tentações. Foi esse um dos intervalos em que vivi em maior calma, e que recordo com o maior prazer. Em diversas situações em que encontrei durante a vida, algumas ficaram marcadas por um tal sentimento de bem-estar, que, ao recordálas, ainda sinto não só o tempo, os lugares, as pessoas, mas todos os objetos circundantes, a temperatura do ar, seu cheiro, sua cor, uma certa impressão local que só lá se faz sentir e cuja viva lembrança de novo me arrebata. Por exemplo, tudo que se ensaiava na escola, tudo que se cantava no coro, tudo que lá se fazia, o belo e nobre hábito dos cônegos, as casulas dos padres, as mitras dos chantres, a cara dos músicos, um velho carpinteiro manco que tocava contrabaixo, um padrezinho louro que tocava violino, o farrapo de sotaina que, depois de ter tirado a espada, o Mestre vestia sobre a roupa leiga, e a linda sobrepeliz fina com que lhe cobria os buracos para ir ao coro. O orgulho com que eu, segurando a minha flautazinha de bico, ia me aboletar na tribuna da orquestra para um trechozinho de música que o Mestre fizera expressamente para mim. O bom jantar que depois nos esperava, e o bom apetite que tínhamos. Esse conjunto de coisas, vivamente delineado, encantou-me cem vezes a memória, tanto ou mais quanto o fez a realidade. Conservei sempre uma afeição terna por uma certa ária do Conditor alme siderum, em jâmbico, porque na madrugada de um domingo de Advento a ouvi da cama, cantada na escada exterior da catedral, conforme um rito dessa igreja. A Srta. Merceret, criada de quarto de mamãe, sabia um pouco de música; e não esqueceria mais um motete, Afferte, que o Sr. Le Maître me fez cantar com ela, e que a patroa ouviu com tanto prazer. Enfim, todos, até Perrina, a criada, tão boa rapariga e que os meninos do coro atormentavam tanto, tudo, nesse tempo de felicidade e inocência, vem frequentemente me encantar e entristecer". Confissões. Livro III, p. 130-131. (N.T.). 
Em todos os seus escritos, Rousseau nunca perdeu a si mesmo de vista. Do começo ao fim, ele foi sempre o mesmo indivíduo. O espírito que movia suas paixões nunca se aquietou; o pulso que agitava o seu coração jamais cessou de bater. É este forte sentimento de interesse reunido em sua mente que subjuga e absorve os sentimentos de seus leitores. De fato, todo o seu poder se deve ao sentimento. O escritor que mais se assemelha a ele nos tempos de hoje é o autor de As Baladas Líricas. Não encontramos nenhuma diferença entre eles senão pelo fato daquele ter escrito em prosa e este, em poesia; e a prosa é talvez mais adequada para expressar aqueles sentimentos locais e pessoais, que são, no fim das contas, hábitos inveterados da mente, enquanto a poesia corporifica as obras da imaginação. Nosso espírito (mind) está mais em casa quando ouve a exclamação de Rousseau, "A $h$, voila de la pervenche" 9 , do que com a descoberta de Wordsworth do ninho do pintarroxo, "with five blue eggs" ao cuco, infinitamente bela em nossa imaginação. Contrastemos confidentemente as aventuras do Cidadão de Genebra no Lago de Bienne com os sonhos flutuantes do poeta de Cumberland no Lago de Grasmere. Ambos fazem surgir um interesse do nada, ou melhor, de suas próprias sensações; ambos tecem suas inúmeras recordações em um único sentimento; ambos enredam o seu ser sobre quaisquer objetos que os assaltem. Mas Rousseau, como escritor de prosa, dá-nos apenas as impressões habituais e pessoais. Wordsworth, como poeta, é forçado a emprestar as cores da imaginação a impressões cuja única força depende exclusivamente de suas identificações consigo mesmas, além de ter de se esforçar para pintar o que deve ser apenas sentido. Numa palavra, Rousseau desperta no outro o interesse por certos objetos ao fazer-nos interessar por ele mesmo; Wordsworth se esforça em persuadir-

9 Confissões, Livro Sexto. (N.T.).

10 Do poema de Wordsworth, The Sparrow's Nest, 1. 1: "Look, five blue eggs are gleaming there!" (N.T.). 
-nos de que os objetos mais insignificantes são interessantes em si mesmos porque o autor se interessa por eles. Tivesse Wordsworth conhecido a pervinca favorita de Rousseau, ele a teria traduzido numa das mais belas flores. Isto não é imaginação, mas falta de sensibilidade. Se sua inveja pela simpatia (sympathy) dos outros evita o que é belo e grandioso na natureza, por que ele se propõe a descrever minuciosamente outros objetos? Sua própria natureza é uma mera Dulcinéia Del Toboso que ele teria transformado na Rainha Vashti. Rubens parecia estar tão extraordinariamente ligado às suas três mulheres quanto Rafael a Fornarina, mas os retratos que o primeiro fez daquelas não são clássicos. Os três maiores egotistas que conhecemos, ou seja, os três escritores que sentiram o seu próprio ser da maneira a mais poderosa e a mais exclusiva foram Rousseau, Wordsworth e Benvenuto Cellini. Como disse Swift algures, desafiamos o mundo com a promessa de um quarto. 
Resumos |Abstracts 



\title{
Ideias estéticas e imaginação poética em Hölderlin
}

Ulisses Razzante Vaccari

Resumo: O presente texto procura investigar o projeto estético de Hölderlin anunciado numa carta a Neuffer como um texto sobre ideias estéticas. A declaração, da mesma carta, de que o ensaio de Schiller Sobre graça e dignidade, apesar de não ter dado o necessário passo além do limite kantiano, teria apontado o caminho certo, servirá como fio condutor da presente investigação, cujo objetivo final é fornecer uma interpretação do fragmento Sobre a lei da liberdade, em que o poeta desenvolve uma fundamentação filosófica da imaginação poética.

Palavras-chave: Ideia Estética, Imaginação Poética, Sensibilidade, Moral.

\begin{abstract}
This paper investigates Hölderlin's aesthetic project announced in a letter to Neuffer as a text on aesthetic ideas. The statement in the same letter that Schiller's essay On grace and dignity, despite not having given the necessary step beyond the Kantian boundary would have pointed the right way, serve as a guideline of this research, whose ultimate goal is to provide an interpretation of the fragment On the law of liberty, in which the poet develops a philosophical foundation of poetic imagination.
\end{abstract}

Keywords: Aesthetic Idea, Poetic Imagination, Sensibility, Moral.

\section{David Hume e o "curioso ajuste das causas finais"}

Resumo: Trata-se, em primeiro lugar, de examinar a parte III dos Diálogos sobre a religião natural de David Hume e de indicar sua importância na economia interna da obra. Em segundo lugar, pretende-se propor uma explicação do texto da parte XII que permita tirar algumas conclusões acerca do estatuto da teleologia ao final dos Diálogos e na filosofia de Hume de modo geral. 
Palavras-chave: Finalismo, Teleologia, Religião Natural, Crença, Experiência, Ceticismo.

Abstract: The paper deals with the role of part III of Hume's Dialogues concerning natural religion in the economy of the book as a whole so as to propose an explanation of part XII that deals adequately with Hume's conception of teleology not only in the Dialogues but in his other works as well.

Keywords: Final causes, Teleology, Natural religion, Belief, Experience, Scepticism.

\section{Da liberdade e da necessidade, ou das ações voluntárias em Hume \\ Maria Adriana Camargo Cappello}

Resumo: O texto examina a concepção humiana de vontade no quadro da teoria das paixões delineada na segunda parte do Tratado da natureza humana, com o objetivo de mostrar como ela responde às exigências da doutrina da liberdade e necessidade tal comos se encontra na Investigação sobre o entendimento humano.

Palavras-chave: Vontade, Paixão, Ações, Liberdade, Necessidade.

Abstract. The paper deals with Hume's conception of will as it is presented in the second book of the Treatise so as to show how it accords with the theory of liberty and necessity delineated in the first Inquiry.

Keywords: Will, Passion, Actions, Liberty, Necessity.

\section{Aquém das miragens: a negatividade no âmago da experiência}

Resumo: Este artigo perscruta o modo pelo qual H. Bergson, em 
As duas fontes da moral e da religião, equaciona o problema da negatividade, em contraposição ao modo pelo qual abordara esse tema em A evolução criadora. Assim, busca-se, primeiramente, explicitar os vínculos estabelecidos pelo autor entre as representações negativas e os imperativos lógicos e pragmáticos, o que atribui a essas imagens um caráter fundamentalmente fictício. Em seguida, a discussão volta-se para a nova conotação que essas representações adquirem na última obra. Aqui, um certo niilismo desponta como algo intrínseco à inteligência. $\mathrm{O}$ caráter ontológico desse niilismo passa então a ser equacionado pelo texto, bem como suas consequências.

Palavras-chave: Negatividade, Elã, Moral, Religião, Clausura.

Abstract: This article investigates the way in which H. Bergson, in Two sources of morality and religion, works with the problem of negativity, in contrast to the way he aproaches this subject in The creative evolution. Firstly, this text aims to clarify the links established, by the author, between the negative representations and the logical and pragmatic injunctions (which attach to these images a fundamentally fictional character). Secondly, the text intends to discuss the new connotation that these representations acquire in the Bergson's last book, where a certain nihilism emerges as something intrinsic to intelligence.

The proposal of this text is to explore the ontological character of this nihilism, as well as its consequences.

Keywords: Negativity, Élan, Moral, Religion, Enclosure.

\section{Genealogia do psíquico. Sobre a A transcendência do ego - esboço de uma descrição fenomenológica, de Jean- Paul Sartre}

Alexandre de Oliveira Torres Carrasco

Resumo: O texto que segue é a segunda parte de um estudo sobre $A$ Transcendência do Ego, esboço de uma descrição fenomenológica, de J.-P. Sartre. O objeto é a concepção sartriana do ego, em referência às tradições cratesiana e fenomenológica. A primeira parte desse estudo foi publicada nos Cadernos Espinosanos, vol. XXVIII, em agosto de 2013. 
Palavras-chave. Transcendência, Ego, Sartre, Fenomenologia.

Abstract: The following paper is the second part of a study concerning Sartre's La transcendence de l'ego. It deals with Sartre's conception of the cogito in reference to the Cartesian and the Phenomenological traditions. The first part of the article was published in Cadernos Espinosanos, vol. XXVIII, August 2013.

Keywords: Transcendency, Ego, Sartre, Phenomenology.

\section{Linguagem e inconsciente em Lacan}

Ana Carolina Soliva Soria

Resumo: O presente texto, que tem como guia as ideias de Jacques Lacan expostas no "Seminário sobre A carta roubada", investiga alguns aspectos da imbricação entre linguagem e inconsciente no pensamento do psicanalista francês.

Palavras-chave: Lacan, Inconsciente, Linguagem, Significante, Significado.

Abstract: The present text, which is based on Jacques Lacan's ideas shown in the "Seminar on The Purloined Letter", looks into some intrinsic aspects between language and unconscious according to the French psychoanalyst's thoughts.

Keywords: Lacan, Unconscious, Language, Signifier, Signified.

\section{Abaixo de zero: psicanálise, política e o "deficit de negatividade" em Axel Honneth}

Vladimir Safatle

Resumo: Trata-se de discutir a natureza dos recursos à psicanálise (em especial Donald Winnicott e Hans Loewald) feitos por Axel Honneth na construção de sua teoria do reconhecimento. Espera-se mostrar 
como tais recursos trazem consequências políticas claras por permitir a definição de um dos eixos fundamentais das lutas sociais como sendo a afirmação das condições para o desenvolvimento da individualidade. Durante o artigo, veremos como o recurso a outra matriz psicanalítica (fornecida por Jacques Lacan) poderia abrir o caminho para consequências políticas alternativas.

Palavras-chave: Reconhecimento, Psicanálise, Honneth, Lacan, Individualidade, Pulsão.

\begin{abstract}
This article aims to discuss the nature of some uses of psychoanalysis (specially Donald Winnicott and Hans Loewald) made by Axel Honneht to built his theory of recognition. We hope to show how these uses have some important political consequences, specially because they open the space to establish the development of individuality as a major axe for social conflicts. In this article, there is also question to show how the philosophical reflextion upon another psychoanalytic tradition (fournished by Jacques Lacan) could open the way to different political consequences.
\end{abstract}

Keywords: Recognition, Psychoanalysis, Honneth, Lacan, Individuality, Drive.

\title{
Sobre o estudo da filosofia indiana
}

Marcus Sacrini

Resumo: A tese geral deste texto é que muitas escolas indianas de pensamento podem fazer parte da formação acadêmica brasileira em filosofia. Afinal, um dos aspectos marcantes das obras filosóficas comumente estudadas em nossas instituições de ensino é a formulação de discursos argumentados, passíveis de aperfeiçoamento por meio de discussões ou debates. Ora, pode-se encontrar vários exemplos desses discursos nos textos produzidos na Índia clássica.

Palavras-chave: Índia Clássica, Discussão, Debate, Conhecimento, Filosofia. 


\begin{abstract}
The general thesis exposed in this paper is that Indian Classical philosophy could be thaght and studied amongst us in the same manner as Western philosophy given that one of its most significant features is the formulation of discourses based on arguments capable of improvement via debate.
\end{abstract}

Keywords: Classical India, Discussion, Debate, Knowledge, Philosophy.

\title{
A concepção metafísica de Descartes da ciência e da representação mecanicista da natureza
}

Resumo: O objetivo é descrever a concepção metafísica da ciência de Descartes como um instrumento de solução de problemas e a construção metafísica do mundo como uma representação mecanicista da natureza. O objetivo do projeto cartesiano é de proporcionar legitimidade ao método de Galileu de física e a imagem da natureza física por ela criada como caracterizando a natureza da ciência e da nova imagem do mundo como mecânica formada de massas e movimento. Descartes transforma a física de Galileu em um modelo e programa de conhecimento do mundo e o mundo numa representação mecânica.

\footnotetext{
Abstract: The aim is describing the rational method of Descartes as a method of problem solving e decision making which led to the construction of the mechanical representation of nature as heuristic as much as rational procedure of problem solving. The aim of Descartes is to transform the method of Galileo into a research program e his conception of world into a new image of world as mechanical representation.
} 


\section{Instruções aos autores | Notes to contributors}

1. Os artigos, resenhas, traduções ou outros materiais devem ser enviados para o endereço seguinte: revistadiscurso@usp.br.

2. Os trabalhos enviados para publicação devem conter no máximo 80 mil toques. As citações e as referências bibliográficas devem obedecer ao padrão adotado a partir do presente número (42).

3. Artigos devem ser acompanhados de resumo de até 100 palavras, em português e em inglês (abstract), palavras-chave em português e em inglês (key words) e bibliografia. As obras citadas devem ser ordenadas alfabeticamente pelo sobrenome do autor.

4. A comissão executiva se reserva o direito de aceitar ou recusar os trabalhos ou ainda de reapresentar o original ao autor com sugestões de mudanças. Os relatores de parecer permanecerão em sigilo.

1. Articles, reviews, translations and other materials must be sent to the following address: revistadiscurso@usp.br

2. All contributions will be considered on the assumption that they have not been integrally published elsewhere. Contributions should not normally exceed 80 thousand characters (with spaces).

3. An abstract of up to 100 words should be attached to the article, together with a choice of key words. A bibliographical list of cited references, beginning with the author's last name, should be placed on a separate sheet in alphabetical order.

4. All articles will be strictly refereed. The editorial board has the last word on which contributions will be accepted, which will be refused and which will be sent back to authors for amendments. 



$\begin{aligned} \text { Revisão } & \text { José Teixeira Neto } \\ \text { Projeto gráfico } & \text { Marcelo Girard } \\ \text { Imagem da capa } & \text { Marcelo Girard } \\ \text { Diagramação } & \mathrm{IMG}_{3} \\ \text { Fontes } & \text { Electra / Times News Roman (textos em hindi) } \\ \text { Papel } & \text { Offset } \\ \text { Gramatura } & 75 \mathrm{~g} / \mathrm{m}^{2} \\ \text { Impressão } & \text { Bartira Gráfica }\end{aligned}$

